\title{
Risk Factor Analysis of Endoscopic Dilation Procedure for the Management of Subglottic Stenosis in Pediatric Patients
}

\author{
Min Hae Park ${ }^{1}$ (D), Nayeon Choi ${ }^{1,2}$ (D), Bok Hyun Song ${ }^{1}$ (D), \\ Han-Sin Jeong, ${ }^{1}$ (D) Young-Ik Son ${ }^{1} \mathbb{D}$, and Man Ki Chung ${ }^{1}$ (D) \\ 'Department of Otorhinolaryngology-Head and Neck Surgery, Samsung Medical Center, Sungkyunkwan University School of Medicine, Seoul, Korea \\ 2Department of Otorhinolaryngology-Head and Neck Surgery, Jeju National University School of Medicine, Jeju, Korea
}

\section{성문하 협착 소아 환자에 대한 내시경적 기도 확장 시술 후 치료 실패 위험 요인 분석}

박민혜 ${ }^{1}$, 최나연 ${ }^{1,2}$, 송복현 ${ }^{1}$, 정한신 $^{1}$, 손영익 ${ }^{1}$, 정만기 ${ }^{1}$

성균관대학교 의과대학 삼성서울병원 이비인후과학교실, ${ }^{1}$ 제주대학교 의과대학 이비인후과학교실2

Background and Objective Endoscopic airway dilation is the primary treatment for pediatric subglottic stenosis (SGS) due to its feasibility and non-invasiveness. The aim of this study is to evaluate the risk factors for the failure of endoscopic airway dilation in pediatric patients with SGS.

Materials and Methods This study reviewed medical records of 38 pediatric patients had endoscopic dilation from a single and tertiary referral center, retrospectively. The success of the endoscopic dilation procedure was defined as no dyspneic symptom without tracheostomy or laryngotracheal reconstruction. Demographic profiles, underlying disease, and Myer-Cotton SGS severity grade were recorded. Success rates and risk factors for the failure of treatment were analyzed.

Results The SGS patients with severity grade I was most common. After mean 1.8 numbers of procedures, there were 23 patients (60.5\%) in the success group and 15 patients (39.5\%) in the failure group. Age, sex, underlying diseases, and SGS severity grade were not significantly different between two groups. In patients who had multiple endoscopic procedures, the failure group showed SGS deteriorated after procedures in $66.7 \%$, compared to $11.1 \%$ of the success group. In multivariable analysis, a long-term intubation ( $\geq 1$ month) was identified as an independent risk factor for failure of endoscopic dilation procedure.

Conclusion Although endoscopic dilation procedure is safe and effective for the management, repetitive endoscopic dilation may not give clinical benefit in patient with long-term intubation. Other airway procedures must be considered in those group of patients.

Keywords Laryngeal stenosis; Subglottic stenosis; Dilation; Endoscopic surgery.

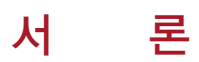

소아의 기도 협착은 선천적 원인으로 발생하기도 하나 기관 삽관 등으로 인한 점막 손

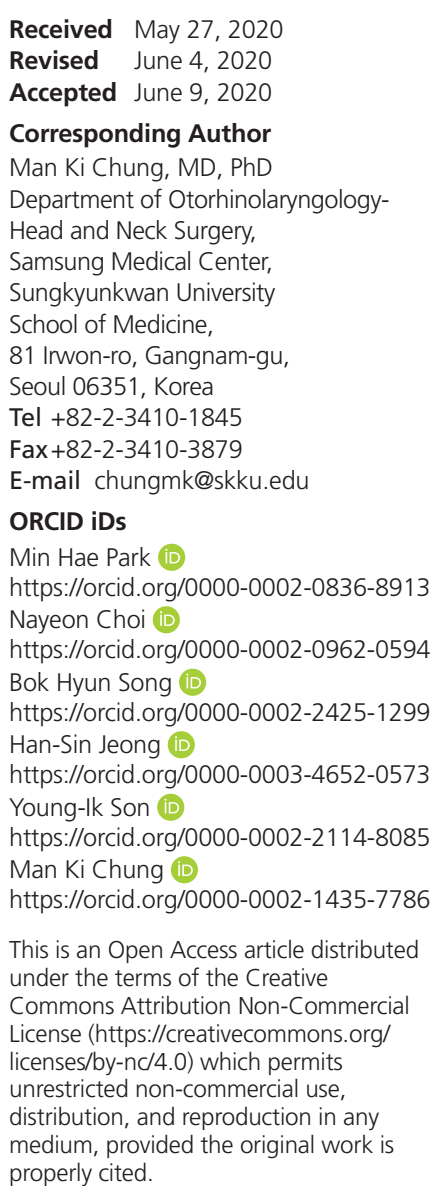


상으로 인하여 후천적으로 발생하는 경우가 더 많다. 특히 기 도에서 직경이 가장 좁은 윤상연골은 원형으로 성문하부 전 체를 둘러싸고 있다. 이러한 구조적 특성으로 성문하부는 압 력 변화에 취약하여 협착이 흔하게 발생한다.

소아의 성문하 기도 협착을 치료하는 방법은 크게 내시경 을 이용하는 비침습적 치료와 침습적 후두재건술이 있다. 비 침습적 치료의 종류는 풍선(balloon)을 이용해 좁아진 부분 을 넓히거나 금속 기구를 이용해 부지(bougie)를 시행하는 방 법이 있다. 침습적 치료로는 후두기관 재건술(laryngotracheal reconstruction), 윤상연골기관 절제술(cricotracheal resection) 기관절제 및 단단문합술(tracheal end-to-end resection and anastomosis), 기관 절개술 등이 있다. ${ }^{1)}$ 이 중 후두기관 재 건술과 윤상연골기관 절제술은 재협착률이 낮고 협착 부위 를 완전 제거함으로써 기관절개공(trahcheostomy) 없이 생활 할 수 있다는 장점이 있으나, 침습적이고 수술을 여러 단계로 나누어 시행한다는 단점이 있다. 반면, 비침습적 기도 확장술 은 협착 부위가 광범위할 경우 협착 부위를 완전히 확장하지 못한다는 단점이 있으나, 외부 절개를 시행하지 않고 단시간 내 시행할 수 있기 때문에 기도 협착의 초기 치료로 선호된다. ${ }^{2}$ 임상에서는 환자요인이나 술자의 선호도 등에 따라 침습적 후 두재건술 대신 반복적으로 비침습적 기도 확장술을 시행하는 경우가 드물지 않은데, 이러한 환자의 기도 협착 변화 및 비침 습적 시술 성공률 등의 임상 결과에 대한 분석은 드물다. ${ }^{3,4}$

본 연구는 단일기관에서 성문하부 협착에 대하여 비침습 적 기도 확장술을 시행 받은 소아 환자를 대상으로 시술의 성 공률 및 시술 실패의 위험요인에 대하여 분석하였다.

\section{대상 및 방법}

\section{대 상}

본 연구는 삼성서울병원 기관윤리심의위원회의 승인을 받 았으며(승인 번호: 2017-09-009), 2010년 1월 2017년 10월까 지 본원에서 치료받은 성문하 협착 환자를 후향적으로 분석 하였다. 연구 대상 포함 기준은 1) 18세 미만의 소아 환자, 2) 성 문하부 이외에 성문상부와 기관 등에 교정을 필요로 하는 동 반 협착이 없을 것, 3) 내시경적 기도 확장술을 시행 받기 이 전에 본원이나 타원에서 후두기관 재건술 등 외부 접근술 (open approach)을 시행 받지 않은 환자로 하였다.

연구 기간 동안 총 42 명의 소아 환자가 기도 협착에 대해서 내시경적 기도 확장술을 시행 받았으며, 이 중 기관 협착(tracheal stenosis), 성대후부 협착(posterior glottic stenosis), 성 문상부 협착(supraglottic stenosis)이 있는 환자는 연구 대상 에서 제외하였으며, 성문하부 협착(subglottic stenosis, SGS)
만 있는 환자는 모두 40 명이었다. 이 중 2 명의 환자는 비침습 적 시술 직후 기저 질환으로 사망하였고, 최종적으로 38 명의 환자를 대상으로 분석하였다.

환자의 성별, 나이, 협착의 원인, 기저 질환, 비침습적 기도 확 장술 술기의 종류, 성문하 협착의 정도, 관찰 기간, 수술 전 기 관절개술 또는 기관 삽관 여부, 수술의 성공 여부 등의 임상 자 료를 수집하였다.

\section{성문하 협착의 평가 및 내시경적 기도 확장술의 방법} 내시경적 기도 확장술을 시행하기 전 성문하 협착의 정도 는 Myer-Cotton 기도 협착 등급 분류법을 이용하여 기술하 였다. Myer-Cotton grade I은 성문하부의 50\% 미만의 협착, grade II는 51 70\%, grade III는 71 99\%, grade IV는 완전 협 착을 나타냈다. ${ }^{5)}$ 모든 환자에서 내시경적 기도 확장술 시행 전 (Fig. 1A)과 시행 후(Fig. 1D) 성문하 상태를 촬영해 협착 호 전 여부를 비교하였다.

내시경적 기도 확장술은 내시경을 이용한 부지와 풍선 확 장술 2가지 방법으로 시행하였다. 부지를 시행한 경우는 술자 의 판단에 따라 협착 부위에 절개를 넣기도 하였으며, 점막 손상을 최소화하고자 $\mathrm{CO}_{2} \mathrm{LASER}$ 등 에너지 도구는 사용하 지 않고 금속 기구만 사용하여 확장술을 시행하였다. 풍선 확 장술은 식도 확장술에 쓰이는 카테터 종류와 동일한 $\mathrm{CRE}^{\mathrm{TM}}$ balloon dilation catheter(Boston Scientific Co, Marlborough, $\mathrm{MA}, \mathrm{USA}$ )를 사용하였으며, 직경 6 8 $\mathrm{mm}$ 중 하나를 선택하 여 사용하였다(Fig. 1B, C). Apneic technique을 적용하여 기 도 삽관을 제거한 다음, 협착 부위에 풍선의 가운데를 위치하 고, 생리식염수를 주입하여 한번에 30초씩, 총 3회 반복 시술 하였다. 협착 부위 반흔조직 제거나 절개 등의 시술을 시행한 경우 재협착을 방지하기 위하여 mitomycin C $0.4 \mathrm{mg} / \mathrm{mL}$ 을 4 분 30 초간 적용하기도 하였다.

\section{수술 결과의 평가}

수술 결과에 따라 내시경적 기도 확장술의 성공군과 실패 군으로 나누었다. 환자의 경과 관찰 종료시점에서 수술의 성 공은 내시경적 기도 확장술 시행 후 기관절개공이나 기관삽 관술이 없이 6개월간 호흡곤란이 없는 상태로 정의하였다. 또 한, 내시경적 기도 확장술을 일회 또는 반복적으로 시행하였 음에도 기도 협착이 진행하여 후두기관 재건술을 시행받는 경우와, 기관절개공을 지속적으로 가지고 있는 환자는 실패군 으로 분류하였다.

\section{통계 분석}

Mann-Whitney 검정이 두 군 간의 연속형 변수를 비교하 

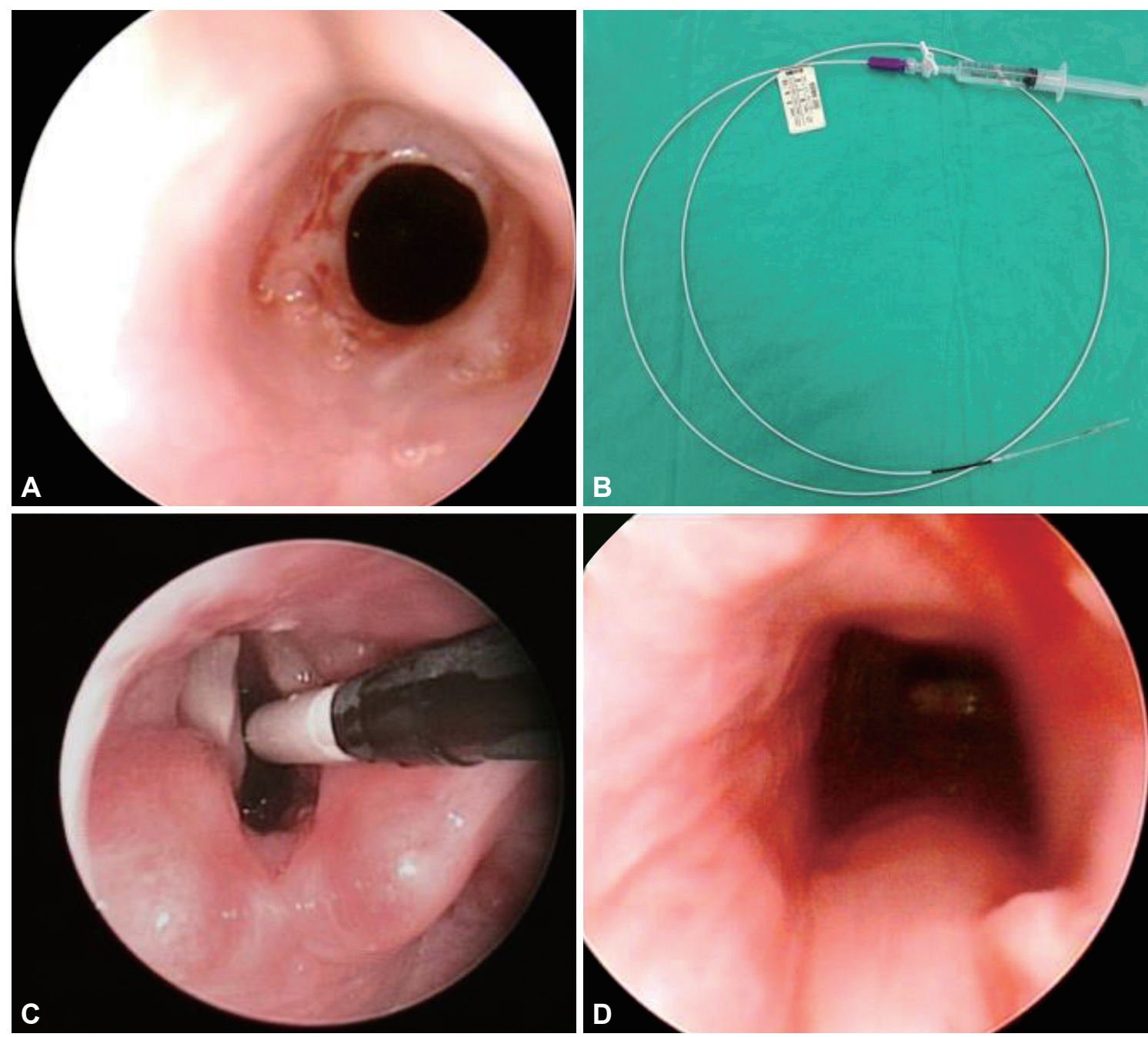

Fig. 1. A representative case of endoscopic balloon dilation procedure in pediatric patient with SGS. A: Endoscopic finding before endoscopic balloon dilation showed SGS severity grade I. B: CRETM balloon dilation catheter (Boston Scientific Co) with a 3-way valve and saline-filled syringe. C: A placement of a center of balloon catheter within the most narrow point in SGS. D: Endoscopic finding after endoscopic balloon dilation. Immediate endoscopic findings after balloon dilation. SGS: subglottic stenosis.

기 위해 사용되었으며, 범주형 변수는 Fisher의 정확 검정을 통하여 비교하였다. 이분 로지스틱 회귀 분석이 수술의 결과에 대한 위험인자를 분석하기 위해 사용되었다. $\mathrm{P}-\mathrm{value}<0.05$ 를 통계학적으로 의미 있는 수치로 정의하였다. 통계 분석은 SPSS for Windows ver. 20.0(IBM Corp., Armonk, NY, USA) 으로 시행하였다.

\section{결 과}

\section{내시경적 기도 확장술 성공군과 실패군 비교}

총 38명의 소아 환자 평균 나이는 $19.5 \pm 35.8$ 개월이며, 26 (68.4\%)명은 남자였고, 12(31.6\%)명은 여자였다(Table 1). 내시 경적 기도 확장술 전 기관 삽관을 유지한 기간은 평균 40.6土 47.3일이다. 기저 질환은 신생아 호흡곤란 증후군(respiratory distress syndrome), 기관지폐 형성이상(bronchopulmonary dysplasia), 후두연화증, 세기관지염 등의 폐질환(71.1\%)이 가장 많았으며, 대혈관 전이, 심장 판막협착 등의 심장 질환(15.8\%) 이 뒤를 이었다. 과거 병력 상 성문하 협착의 원인으로는 원인 미상이 9명(23.7\%)이고, 기저 질환 치료 등 목적의 기관 삽관 술로 인한 후천성 협착이 29명(76.3\%)이었다. Myer-Cotton grading 시스템으로 평가한 성문하 기도 협착 정도는, grade I 이 24명(63.2\%), grade II가 8명(21.1\%), grade III가 5명(15.8\%) 이였다. 평균적으로 1.8 회 내시경적 기도 확장술이 시행되었 고, 시술 후 경과 관찰 기간은 $41.1 \pm 33.9$ 개월이었다. 최종 추 적관찰 시점에서 내시경적 기도 확장술이 성공한 환자는 23명 (60.5\%)이고, 실패한 환자는 15 명(39.5\%)이다. 내시경적 기도 확장술에 실패한 15 명의 환자 중 9 명은 기관 절개술 후 발관 에 성공하여 증상 없이 지내고 있으며, 3 명은 기관 절개 후 캐 
뉼라를 유지하고 있고, 3명은 후두기관 재건술을 받았다.

내시경적 기도 확장술의 성공군과 실패군을 비교하였을 때, 두 군간 나이와 성별은 통계학적으로 의미 있는 차이는 관 찰되지 않았다. 성공군에서 내시경적 기도 확장술은 $1.6 \pm 0.2$ 회, 실패군에서는 $2.1 \pm 0.3$ 회 시행되었으며, 통계학적으로 의
미 있는 차이는 없었다. 수술 전 기관 삽관을 시행하고 있던 기 간은 성공군이 $28.8 \pm 6.6$ 일, 실패군이 $58.7 \pm 15.9$ 일이었으며, 두 군 간 기관 삽관 기간에서 통계학적으로 의미는 보이지 않 았다 $(\mathrm{p}=0.107)$. 기관 삽관 기간을 1 개월 미만과 1 개월 이상으로 분류하였을 때' ${ }^{6}$ 성공군과 실패군 간 분포에 통계적으로 유의

Table 1. Study patients $(n=38)$

\begin{tabular}{|c|c|c|c|c|}
\hline Variables & $\mathrm{n}=38$ & Success $(\mathbf{n}=23)^{*}$ & Failure $(\mathrm{n}=15)^{*}$ & p-value \\
\hline Age (months) & $19.5 \pm 35.8$ & $20.6 \pm 37.4$ & $17.9 \pm 34.5$ & 0.964 \\
\hline $\operatorname{Sex}(M: F)$ & $26(68.4): 12(31.6)$ & $15(65.2): 8(34.8)$ & $11(73.3): 4(26.7)$ & 0.728 \\
\hline Intubation period (days) & $40.6 \pm 47.3$ & $28.8 \pm 6.6$ & $58.7 \pm 15.9$ & 0.107 \\
\hline$<1$ month & & $16(69.6)$ & $5(33.3)$ & \multirow{2}{*}{0.028} \\
\hline$\geq 1$ month & & $7(30.4)$ & $10(66.7)$ & \\
\hline Underlying disease & & & & 0.631 \\
\hline Cardiac & $6(15.8)$ & $3(13.0)$ & $3(20.0)$ & \\
\hline Pulmonary & $27(71.1)$ & $17(73.9)$ & $10(66.7)$ & \\
\hline Craniofacial anomaly & $1(2.6)$ & $0(0)$ & $1(6.7)$ & \\
\hline Oncologic & $3(7.9)$ & $2(8.7)$ & $1(6.7)$ & \\
\hline Trauma & $1(2.6)$ & $1(4.3)$ & $0(0)$ & \\
\hline Cause of stenosis & & & & 0.666 \\
\hline Idiopathic:acquired & $9(23.7): 29(76.3)$ & $6(26.1): 17(73.9)$ & $3(20.0): 12(80.0)$ & \\
\hline Severity of SGS ${ }^{\dagger}$ & & & & 0.273 \\
\hline Grade I & $24(63.2)$ & $15(62.2)$ & $9(60.0)$ & \\
\hline Grade II & $8(21.1)$ & $6(26.1)$ & $2(13.3)$ & \\
\hline Grade III & $6(15.8)$ & $2(8.7)$ & $4(26.7)$ & \\
\hline Number of procedure & $1.8 \pm 1.1$ & $1.6 \pm 0.2$ & $2.1 \pm 0.3$ & 0.146 \\
\hline Follow-up (months) & $41.1 \pm 33.9$ & $32.7 \pm 21.1$ & $54.2 \pm 42.7$ & \\
\hline
\end{tabular}

Data are presented as $\mathrm{n}(\%)$ or mean $\pm \mathrm{SD}$. *Success of the endoscopic dilation procedure was defined that patients had no dyspnea until 6 months after endoscopic airway dilation without tracheostomy, intubation, or laryngotracheal reconstruction, ${ }^{\dagger}$ Cotton-Myer grading system. SD: standard deviation, SGS: subglottic stenosis

Table 2. Comparisons between the success and failure group in patients who had multiple endoscopic dilatation procedures ( $n=18)$

\begin{tabular}{|c|c|c|c|}
\hline Variables & Success $(\mathrm{n}=9)^{*}$ & Failure $(\mathrm{n}=9)^{*}$ & p-value \\
\hline Age (months) & $18.6 \pm 25.5$ & $5.3 \pm 6.2$ & 0.150 \\
\hline Sex (M:F) & $7(77.8): 2(22.2)$ & $7(77.8): 2(22.2)$ & 1.000 \\
\hline Intubation period (days) & $37.3 \pm 25.4$ & $52.0 \pm 49.5$ & 0.445 \\
\hline Underlying disease & & & 0.294 \\
\hline Pulmonary & $8(88.9)$ & $5(55.6)$ & \\
\hline Cardiac & $1(11.1)$ & $3(33.3)$ & \\
\hline Craniofacial anomaly & $0(0)$ & $1(11.1)$ & \\
\hline Oncologic & $0(0)$ & $0(0)$ & \\
\hline Trauma & $0(0)$ & $0(0)$ & \\
\hline Cause of stenosis & & & 1.000 \\
\hline Idiopathic:acquired & $0(0): 9(100)$ & $1(11.1): 8(88.9)$ & \\
\hline Severity of SGS ${ }^{\dagger}$ & & & 0.658 \\
\hline Grade I & $6(66.7)$ & $5(55.6)$ & \\
\hline Grade II & $2(22.2)$ & $1(11.1)$ & \\
\hline Grade III & $1(11.1)$ & $3(33.3)$ & \\
\hline Number of procedure & $3.4 \pm 1.7$ & $3.4 \pm 2.0$ & 1.000 \\
\hline
\end{tabular}

Data are presented as $\mathrm{n}(\%)$ or mean $\pm \mathrm{SD}$. *Success of the endoscopic dilation procedure was defined that patients had no dyspnea until 6 months after endoscopic airway dilation without tracheostomy, intubation, or laryngotracheal reconstruction, ${ }^{\dagger}$ Cotton-Myer grading system. SD: standard deviation, SGS: subglottic stenosis 
한 차이가 있었다 $(\mathrm{p}=0.028)$. 실패군이 성공군에 비하여 1 개월 이상의 기관 삽관력이 있던 환자가 유의하게 많았다.

두 군간 기저 질환의 분포는 차이가 없었으며, 성문하 협착 의 원인 분포 또한 통계학적으로 의미 있는 차이는 없었다. 성 문하 기도 협착은 성공군과 실패군에서 모두 grade I이 각각 $62.2 \%$ 와 $60.0 \%$ 로 가장 많았으며, 기도 협착 정도의 분포 또한 두 군간 차이는 보이지 않았다.

\section{반복적으로 내시경적 기도 확장술을 시행한 환자에서}

\section{기도 협착의 변화 패턴}

2회 이상 내시경적 기도 확장술을 시행한 환자는 성공군과 실패군에서 각 9명씩 있었다. 반복적으로 시술을 시행한 환자 를 대상으로 성공군과 실패군 간 임상적 요인을 비교했을 때,
유의미한 차이는 보이지 않았다(Table 2). 하지만, 반복적 시 술 과정에서 성문하 협착 정도의 변화, 즉, 각 환자에서의 첫 번째 시술 전 평가된 성문하 협착 정도와 마지막 시술 전 평가 된 성문하 협착 정도를 비교하여 분석하였을 때, 두 군 간에 성문하 협착 정도의 변화가 서로 다른 양상을 보였다(Fig. 2, Table 3). 성공군에서 첫 번째 시술에 비해서 마지막 시술 시 성문하 협착이 호전된 환자는 3명(33.3\%)이였고, 변화가 없었 던 환자는 5명(55.6\%), 악화된 환자는 1명(11.1\%)이였다. 반면 에 실패군에서는 호전된 환자는 1명(11.1\%), 변화가 없는 환자 는 2명(22.2\%), 악화한 환자는 6명(66.7\%)이였다. 실패군에서 통계학적으로 의미 있는 차이로 성문하 협착이 증가한 경우가 더 많았으며, 두 군간 성문하 협착 변화의 분포는 통계학적으 로 의미 있는 차이를 보였다 $(\mathrm{p}=0.025)$.
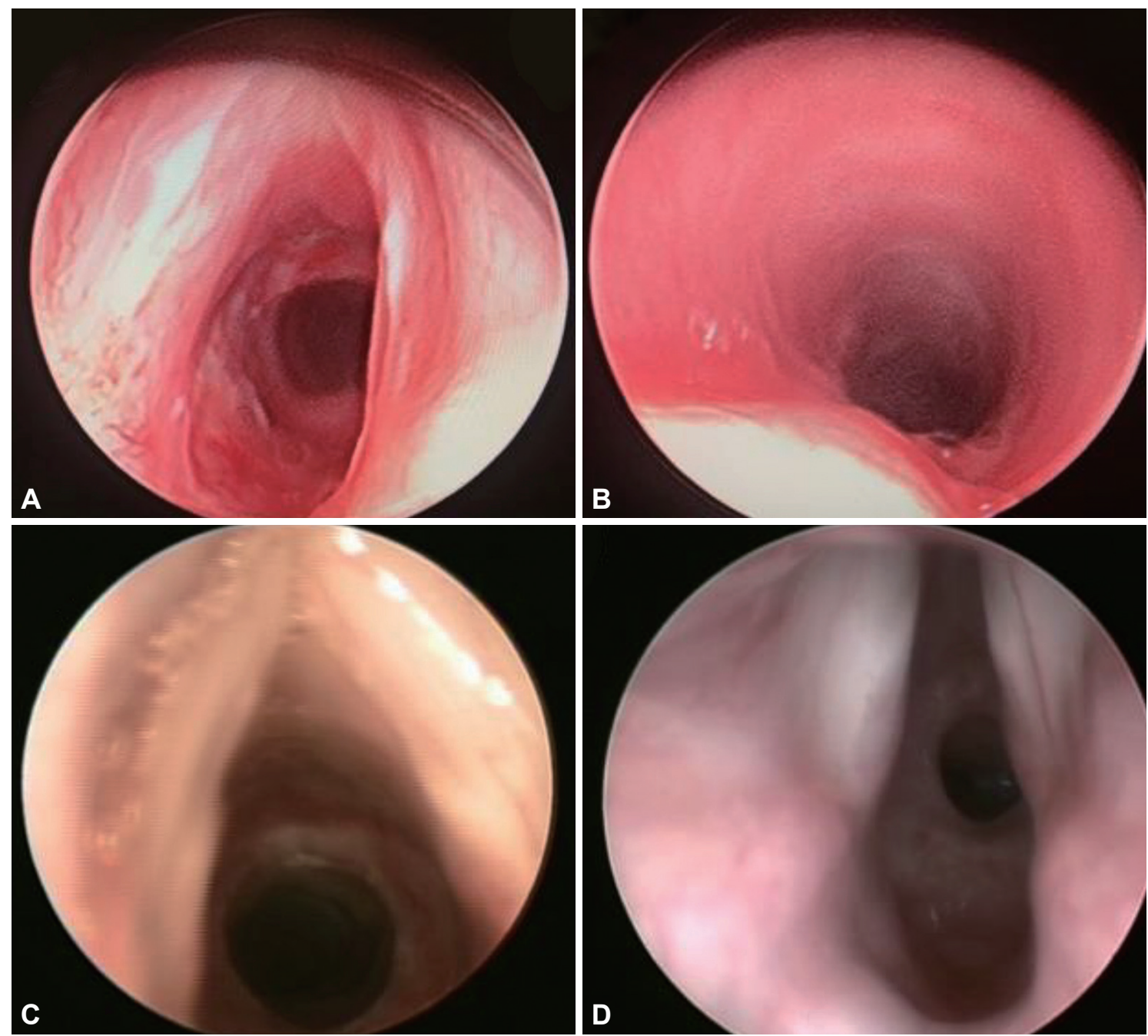

Fig. 2. Representative cases of endoscopic dilation procedure in pediatric patients. A, B: Successful endoscopic balloon dilation procedure in 1-month-old patients who had been intubated for 7 days. A: Endoscopic finding before balloon dilation showed SGS grade I. B: Immediate endoscopic findings after balloon dilation. C, D: The patient who had history of 33 days of intubation period failed subglottic dilation in spite of 4 times of endoscopic surgery. C: Endoscopic finding of initial subglottic dilation when patient was 7 months old showed SGS grade I. D: Endoscopic finding of 3rd dilation procedure when patient was 14 months old demonstrated SGS grade II. After failure of 4th balloon dilation, the patient underwent tracheostomy. SGS: subglottic stenosis. 
Table 3. Comparisons of SGS severity change between initial and last state in patients who had multiple endoscopic procedures $(n=18)$

\begin{tabular}{|c|c|c|c|c|c|c|c|c|c|}
\hline \multirow{2}{*}{ Initial grade of SGS* } & \multicolumn{4}{|c|}{ Success $(n=9)^{\dagger}$} & \multicolumn{4}{|c|}{ Failure $(n=9)^{\dagger}$} & \multirow{2}{*}{ p-value } \\
\hline & I & II & III & IV & I & II & III & IV & \\
\hline I & 4 & 1 & 0 & 0 & 0 & 5 & 0 & 0 & \\
\hline II & 2 & 1 & 0 & 0 & 0 & 0 & 0 & 1 & \\
\hline III & 1 & 0 & 0 & 0 & 0 & 1 & 2 & 0 & \\
\hline Severity change of SGS (n) & & & & & & & & & 0.025 \\
\hline Improved & & \multicolumn{2}{|c|}{$3(33.3)$} & & & \multicolumn{2}{|c|}{$1(11.1)$} & & \\
\hline No change & & \multicolumn{2}{|c|}{$5(55.6)$} & & & \multicolumn{2}{|c|}{$2(22.2)$} & & \\
\hline Worsened & & \multicolumn{2}{|c|}{$1(11.1)$} & & & \multicolumn{2}{|c|}{$6(66.7)$} & & \\
\hline
\end{tabular}

${ }^{*}$ Cotton-Myer grading system, ${ }^{\dagger}$ Success of the endoscopic dilation procedure was defined that patients had no dyspnea until 6 months after endoscopic airway dilation without tracheostomy, intubation, or laryngotracheal reconstruction. SGS: subglottic stenosis

Table 4. Univariate and multivariate analyses of risk factors for the failure of endoscopic dilation procedure

\begin{tabular}{|c|c|c|c|c|c|c|}
\hline & \multicolumn{3}{|c|}{ Univariate analysis } & \multicolumn{3}{|c|}{ Multivariate analysis } \\
\hline & HR & $95 \% \mathrm{CI}$ & p-value & HR & $95 \% \mathrm{CI}$ & p-value \\
\hline Age (1-month increase) & 0.998 & $0.979-1.017$ & 0.816 & & & \\
\hline Male vs. Female & 0.682 & $0.163-2.850$ & 0.600 & & & \\
\hline Number of surgery & 1.614 & $0.851-3.062$ & 0.143 & & & \\
\hline Intubation period ( $<1$ month vs. $\geq 1$ month) & 4.250 & $1.058-17.070$ & 0.041 & 7.102 & $1.368-36.863$ & 0.020 \\
\hline \multicolumn{7}{|l|}{ Underlying disease } \\
\hline Pulmonary & Reference & & & & & \\
\hline Cardiac & 0.588 & $0.099-3.491$ & 0.559 & & & \\
\hline Craniofacial anomaly & 1.811 & $0.001-1.812$ & 1.000 & & & \\
\hline Oncology & 0.500 & $0.028-8.952$ & 0.638 & & & \\
\hline Trauma & 0.003 & $0.001-0.005$ & 1.000 & & & \\
\hline Acquired vs. congenital & 1.412 & $0.294-6.790$ & 0.667 & & & \\
\hline Balloon vs. bougie & 0.955 & $0.259-3.514$ & 0.944 & & & \\
\hline \multicolumn{7}{|l|}{ Initial grade of SGS* } \\
\hline I & Reference & & & Reference & & \\
\hline II & 0.556 & $0.092-3.365$ & 0.522 & 0.242 & $0.032-1.844$ & 0.171 \\
\hline III & 3.333 & $0.202-22.017$ & 0.211 & 4.011 & $0.506-31.821$ & 0.189 \\
\hline
\end{tabular}

${ }^{*}$ Cotton-Myer grading system. HR: hazard ratio, CI: confidence interval, SGS: subglottic stenosis

\section{단변량 및 다변량 로지스틱 회귀 분석을 통한 비침습적} 기도 확장술 실패 위험인자의 분석

단변량 분석에서 나이, 성별, 수술 횟수, 기저 질환, 협착의 원인과 성문하 협착의 정도는 의미 있는 위험인자가 아니었다 (Table 4). 기관 삽관 후 성문하 협착이 발생한 환자를 대상으 로 시행한 선행 연구에서 성문하 협착 환자들의 기관 삽관 기 간의 평균이 30 일이라는 보고가 있어 1 개월 이상의 기관삽관 력을 기준으로 분석을 시행하였을 때, 1 달 이상의 기관삽관 병 력은 의미 있는 위험인자로 확인되었다(위험비: $4.250,95 \%$ 신 뢰구간: 1.058 17.070, $\mathrm{p}=0.041)$. 다변량 분석에서도 마찬가지 로, 1 달 이상의 기관 삽관 병력이 의미 있는 위험인자로 확인되 었다. 1달 미만의 기관 삽관 병력을 기준으로 할 때, 1 달 이상 삽 관을 시행한 환자는 위험비가 7.102배(95\% 신뢰구간: 1.368 $36.863, \mathrm{p}=0.020)$ 로 분석되었다.

\section{고 찰}

소아의 성문하 협착은 호흡곤란 등의 심각한 합병증을 유 발할 수 있기 때문에 적절한 평가 및 치료가 중요하다. 침습적 후두재건수술에 비하여 비침습적 기도 확장술은 절개 없이 성문하 협착을 치료할 수 있으며 반복적으로 시행할 수 있다 는 장점 때문에 소아 성문하 협착의 초치료로 시행되고 있다. 두 치료법에 대하여 후향적 비교를 시행한 연구는 있으나, 아 직 각 치료를 적용하는 정확한 기준은 없는 상태이다. $3 ., 7-9)$

소아의 기도 확장술에 관한 메타분석에 의하면, $65.3 \%$ 의 환자에서 기관절개술이나 후두기관 재건술 없이 성공적인 수 술 결과를 얻을 수 있었다. ${ }^{2}$ 이 메타 분석에서 고찰된 논문들 의 수술 성공률은 54 100\%까지 매우 다양하게 나타났으며, 내시경적 기도 확장술의 성공은 성문하 협착의 정도, 폐질환의 
동반 등 다양한 임상 인자들이 연관되었다고 보고되었다.,10) 특히, 성문하 협착 정도는 내시경적 기도 확장술의 성공과 관 계된 인자로 대부분의 연구들에서 공통적으로 보고하고 있었 으나 ${ }^{8,9)}$ 본 연구에서는 내시경적 기도 확장술 성공군과 실패 군 간 협착 정도에 유의한 차이는 없었다. 본 연구의 술자들은 Cotton-Meyer 성문하 협착 grade I II의 환자들을 내시경 확 장술을 우선적으로 시행하였고, grade III 성문하 협착 경우 에는 협착의 범위가 짧은 경우 내시경 확장술 대상으로 포함 하였다. 성문하 협착에 대한 저자들의 수술 적응 기준이 있었 으며, 선행 연구에 비하여 연구에 포함된 환자 수가 적었기 때 문에 성공군과 실패군 간 성문하 협착 분포의 차이가 없었던 것으로 사료된다.

본 연구에서 주목할 만한 점은 다변량 분석에서 1 달 이상 의 기관 삽관력이 내시경적 기도 확장술 실패의 유일한 위험 인자로 분석되었다는 것이다. 기관 삽관은 성문하부에 압력 손상을 주어 섬유화를 진행시키고 기도 협착을 유발할 수 있 다. ${ }^{11)}$ 기관 삽관력이 있는 Myer-Cotton grade III 이상의 환자 를 대상으로 시행한 연구 결과에 따르면, 성문하부 조직에서 상피 화생, 탄성 섬유의 감소가 공통적으로 관찰되었다. ${ }^{12)}$ 선 행 연구에서도 장기간의 기관 삽관은 성문하 협착의 주요한 위험 인자로 나타났다. ${ }^{13)}$ 그러나 본 연구에서는 반복적, 장기 간 기관 삽관을 시행할 수 밖에 없었던 기저질환의 중증도를 고려하지 않았기 때문에 향후 연구를 진행하게 된다면 이 부 분의 보완이 필요하다.

반복적으로 시행되는 기도 확장술 또한 압력 손상을 누적 시켜 오히려 기도 협착을 유발할 수 있다. 선행 연구에 따르면, 2 회 이상의 반복적인 시술이 내시경적 기도 확장술의 실패 인 자로 보고된 바 있다." 반복된 시술로 인한 압력 손상은 섬유 아세포의 분화와 콜라겐 형성을 촉진시켜 재협착과 반흔 형성 에 영향을 주는 것으로 나타났으며, 항생제와 스테로이드, $\mathrm{mi}^{-}$ tomycin의 사용이 이러한 작용을 저해하는데 도움을 준다는 보고가 있다. ${ }^{3,14,15)}$ 본 연구에서도 실패군에서 반복적으로 확 장술을 시행함에 따라 기도 협착이 증가하는 것이 관찰되었 다. 내시경적 기도 확장술을 시행함에도 불구하고 기도 협착 이 증가하는 것은 확장술의 풍선 압력에 의한 기도 점막 손상 이 원인이 될 수 있다고 가정할 수 있으며, 이에 대해서는 추가 연구가 필요하다.

소아 성문하 협착 환자에서 내시경적 기도 확장술은 1 차 치 료로 가장 많이 시행되며, 수술 전 평가를 통해 내시경적 기도 확장술에 적절한 환자를 선택을 하면 성공적인 결과를 얻을 수 있다. 그러나 압력 외상에 취약한 기관 구조를 가지고 있는 소아 환자에서는 기관 삽관의 기간이 길어짐에 따라 기관 내 협착이 심화되었을 가능성이 높기 때문에, 시술 전 환자 평가
를 면밀히 시행하여 내시경적 기도 확장술이 성공할 가능성 이 낮게 평가되는 환자는, 반복적인 내시경 시술보다는, 조기 에 기관절개술 후 발관 또는 후두기관 재건술을 하는 것이 치 료의 성공률을 높일 수 있겠다.

\section{결 론}

소아 성문하 협착 환자에서 내시경적 기도 확장술은 1 차 치 료로 가장 많이 시행된다. 본 연구의 결과, 내시경적 기도 확장 술의 성공군과 실패군 간 성문하 협착 정도의 차이는 없었다. 그러나 반복적으로 내시경 확장술을 시행했으나 치료에 실패 했던 환자들은 시술을 시행할수록 성문하 협착 정도가 증가 하는 것을 관찰하였다. 또한, 1 개월 이상의 기관 삽관은 내시 경적 기도 확장술 실패의 위험인자로 확인되었다. 따라서 장기 간의 기관 삽관력이 있는 환자에서 반복적인 내시경적 기도 확장술을 시행하는 것은 시술 성공의 가능성이 낮기 때문에 조기 기관절개술 후 발관 또는 후두기관 재건술을 보다 적극 고려해야 한다.

중심 단어: 기도 협착, 성문하 협착, 확장술, 내시경 수술.

Acknowledgments

None.

Conflicts of Interest

The authors have no financial conflicts of interest.

Authors' Contribution

Conceptualization: Man Ki Chung, Nayeon Choi, Min Hae Park. Data curation: Min Hae Park, Bok Hyun Song. Methodology: Man Ki Chung, Nayeon Choi. Investigation: Man Ki Chung, Nayeon Choi, Min Hae Park. Writing: Nayeon Choi, Min Hae Park. Approval of final manuscript: all of authors

\section{REFERENCES}

1. Hartnick CJ, Hartley BE, Lacy PD, Liu J, Willging JP, Myer CM 3rd, et al. Surgery for pediatric subglottic stenosis: disease-specific outcomes. Ann Otol Rhinol Laryngol 2001;110(12):1109-13.

2. Lang M, Brietzke SE. A systematic review and meta-analysis of endoscopic balloon dilation of pediatric subglottic stenosis. Otolaryngol Head Neck Surg 2014;150(2):174-9.

3. Quesnel AM, Lee GS, Nuss RC, Volk MS, Jones DT, Rahbar R. Minimally invasive endoscopic management of subglottic stenosis in children: success and failure. Int J Pediatr Otorhinolaryngol 2011;75(5): 652-6.

4. Hautefort C, Teissier N, Viala P, Van Den Abbeele T. Balloon dilation laryngoplasty for subglottic stenosis in children: eight years' experience. Arch Otolaryngol Head Neck Surg 2012;138(3):235-40.

5. Myer CM 3rd, O'Connor DM, Cotton RT. Proposed grading system for subglottic stenosis based on endotracheal tube sizes. Ann Otol Rhinol Laryngol 1994;103(4 Pt 1):319-23.

6. Rodríguez H, Cuestas G, Botto H, Cocciaglia A, Nieto M, Zanetta A. Post-intubation subglottic stenosis in children. Diagnosis, treatment and prevention of moderate and severe stenosis. Acta Otorrinolarin- 
gol Esp 2013;64(5):339-4.

7. Whigham AS, Howell R, Choi S, Peña M, Zalzal G, Preciado D. Outcomes of balloon dilation in pediatric subglottic stenosis. Ann Otol Rhinol Laryngol 2012;121(7):442-8.

8. Oh SK, Park KN, Lee SW. Long-term results of endoscopic dilatation for tracheal and subglottic stenosis. Clin Exp Otorhinolaryngol 2014; 7(4):324-8.

9. Maresh A, Preciado DA, O'Connell AP, Zalzal GH. A comparative analysis of open surgery vs endoscopic balloon dilation for pediatric subglottic stenosis. JAMA Otolaryngol Head Neck Surg 2014;140(10): 901-5.

10. Avelino M, Maunsell R, Jubé Wastowski I. Predicting outcomes of balloon laryngoplasty in children with subglottic stenosis. Int J Pediatr Otorhinolaryngol 2015;79(4):532-6.

11. Benjamin B. Prolonged intubation injuries of the larynx: endoscopic diagnosis, classification, and treatment. Ann Otol Rhinol Laryngol 2018;127(8):492-507.

12. Duynstee ML, de Krijger RR, Monnier P, Verwoerd CD, VerwoerdVerhoef HL. Subglottic stenosis after endolaryngeal intubation in infants and children: result of wound healing processes. Int J Pediatr Otorhinolaryngol 2002;62(1):1-9.

13. Cakir E, Atabek AA, Calim OF, Uzuner S, AlShadfan L, Yazan H, et al. Post-intubation subglottic stenosis in children: analysis of clinical features and risk factors. Pediatr Int 2020;62(3):386-9.

14. Smith ME, Elstad M. Mitomycin C and the endoscopic treatment of laryngotracheal stenosis: are two applications better than one?. Laryngoscope 2009;119(2):272-83.

15. Warner D, Brietzke SE. Mitomycin C and airway surgery: how well does it work? Otolaryngol Head Neck Surg 2008;138(6):700-9. 